The President of the Malaysian Red Crescent, Tunku Tan Sri Mohamed bin Tunku Besar Burhanuddin, who was accompanied by Datin Ruby Lee, the Society's General Secretary, received the Nansen Medal from the hands of the United Nations High Commissioner for Refugees. In his speech of thanks, the President stressed that the honour was conferred on all 40,000 members of his Society.

The whole Red Cross movement is extremely pleased with the distinction won by the Malaysian Red Crescent Society, and expresses its warm congratulations.

\title{
THE RED CROSS TEACHING GUIDE
}

The Red Cross Teaching Guide is an educational manual designed for secondary school teachers throughout the world. It is presented in the form of a collection of separate papers on a number of subjects, put together in a cardboard box-folder. Each one contains an explanatory text on the subject dealt with, one or two texts for reading (chosen, for example, from the works of Henry Dunant) or a narrative (often describing a mission carried out by an ICRC delegate), statistics (on Red Cross relief distribution, etc.), maps and photographic illustrations. Apart from these texts and documents, the files and dossiers give explanations and suggestions for the way the teacher can take up a particular topic in the classroom, as part of a course on one of a wide variety of subjects, such as history, geography, mathematics, etc., and help him or her to find facts and references that can be introduced into the teaching.

Each paper can be adapted to the special needs and circumstances of the country in which the guide is to be used, and National Societies may insert such modifications and additions as they consider necessary, on the pages that have been left blank. 
IN THE RED CROSS WORLD

The plan of the guide is as follows:

\section{Information Files}

- The Red Cross in action (a lecture by Pierre Boissier, constituting a general introduction).

A. History of the Red Cross

B. The ICRC

C. The Central Tracing Agency

D. The Geneva Conventions

E. The League of Red Cross Societies

F. The National Society (this chapter will be provided by each Society).

G. The International Red Cross

\section{Study Dossiers}

I. The Red Cross and war

II. The Red Cross, human rights and humanitarian principles

III. Red Cross and peace

IV. Red Cross and natural disasters

V. Red Cross and communications

VI. Red Cross and health and social welfare

VII. Red Cross and blood donation

VIII. Red Cross and youth

\section{Summary dossier}

Papers on the themes: "Red Cross: an idea and action," "Red Cross: a state of mind, an attitude," "Red Cross: its unifying force."

\section{Teaching outlines}

These indicate how teaching about the Red Cross can be introduced into courses in history, geography, philosophy, civics, science, etc. As a follow-up to the school text book designed for small children, the Red Cross teaching guide is intended to bring knowledge of the Red Cross to older children who have already gone through primary School. 
The League of Red Cross Societies and the ICRC have co-operated very closely in working out the Teaching Guide, which was published in September of this year. The Documentation and Dissemination Division of the ICRC and the League Youth Bureau had numerous meetings during the preceding months, to plan the project and work out the texts, each bringing to the task the specific knowledge and experience of their respective institutions.

The Teaching Guide, for the moment, has been issued only in English and French for the purpose of initiating the project. It is hoped that the various National Societies and Governments interested in the scheme will produce national editions adapted to their own countries. Further versions in other languages will be considered depending on the reception accorded to the Guide.

M. $T$. 